Document downloaded from:

http://hdl.handle.net/10251/165409

This paper must be cited as:

Ferri-Vicedo, P.; Li, C.; Millán-Cabrera, R.; Martínez-Triguero, J.; Moliner Marin, M.; Boronat Zaragoza, M.; Corma Canós, A. (2020). Impact of Zeolite Framework Composition and Flexibility on Methanol-To-Olefins Selectivity: Confinement or Diffusion?. Angewandte Chemie International Edition. 59(44):19708-19715. https://doi.org/10.1002/anie.202007609

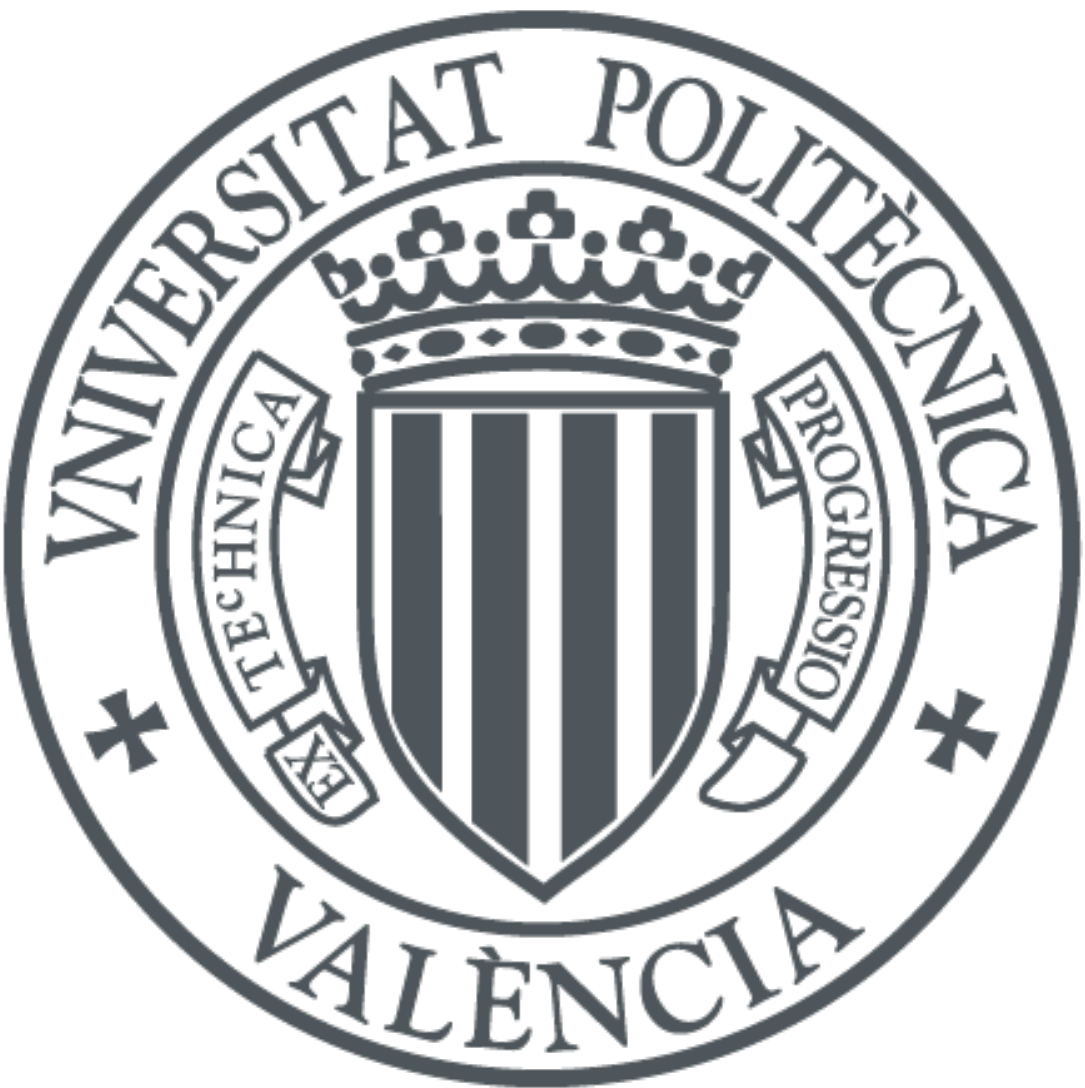

The final publication is available at

https://doi.org/10.1002/anie.202007609

Copyright John Wiley \& Sons

Additional Information

This is the peer reviewed version of the following article: P. Ferri, C. Li, R. Millán, J. Martínez-Triguero, M. Moliner, M. Boronat, A. Corma, Angew. Chem. Int. Ed. 2020, 59, 19708, which has been published in final form at https://doi.org/10.1002/anie.202007609. This article may be used for non-commercial purposes in accordance with Wiley Terms and Conditions for Self-Archiving. 


\title{
Impact of zeolite framework composition and flexibility on MTO selectivity: confinement or diffusion?
}

\author{
Pau Ferri, Chengeng Li, Reisel Millán, Joaquín Martínez-Triguero, Manuel Moliner, Mercedes \\ Boronat, ${ }^{*}$ Avelino Corma*
}

\author{
P. Ferri, C. Li, R. Millán, Dr. J. Martínez-Triguero, Dr. M. Moliner, Dr. M. Boronat, Dr. A. Corma \\ Instituto de Tecnología Química \\ Universitat Politècnica de València - Consejo Superior de Investigaciones Cientificas (UPV-CSIC) \\ Av. de los Naranjos, s/n, 46022 Valencia, Spain \\ E-mail: boronat@itq.upv.es, acorma@itq.upv.es
}

Supporting information for this article is given via a link at the end of the document.

\begin{abstract}
The methanol-to-olefins reaction catalyzed by small-pore cage-based acid zeolites and zeotypes produces a mixture of short chain olefins, whose selectivity to ethene, propene and butene varies with the cavity architecture and with the framework composition. The product distribution of aluminosilicates and silicoaluminophosphates with the CHA and AEI structures (H-SSZ-13, H-SAPO-34, H-SSZ-39 and $\mathrm{H}-\mathrm{SAPO}-18$ ) has been experimentally determined, and the impact of acidity and framework flexibility on the stability of the key cationic intermediates involved in the mechanism and on the diffusion of the olefin products through the $8 \mathrm{r}$ windows of the catalysts has been evaluated by means of periodic DFT calculations and $a b$ initio molecular dynamics simulations. The preferential stabilization by confinement of fully methylated hydrocarbon pool intermediates favoring the paring pathway is the main factor controlling the final olefin product distribution.
\end{abstract}

\section{Introduction}

The methanol-to-olefins (MTO) reaction is an effective process to obtain short chain alkenes such as ethene, propene and butene at an industrial scale. ${ }^{[1,2]}$ The catalysts employed for the MTO reaction are acid zeolites (aluminosilicates) and SAPOs (silicoaluminophosphates) which, besides containing Brönsted acid centers, are able to host within their inorganic structure organic species that co-catalyze the reaction. ${ }^{[3-6]}$ In particular, framework structures containing large internal cavities or cages connected by small 8-membered rings (8r), such as H-SAPO-34, are successfully used in commercial plants since 2010. ${ }^{[2,7]}$

The accepted dual-cycle mechanism for the MTO reaction assumes the formation, during an initial induction period, of organic hydrocarbon-pool (HP) species, either alkenes or aromatics, that remain trapped inside the cavities and participate in the formation of olefins by successive methylation and cracking steps. ${ }^{[8-12]}$ The HP species in small-pore cage-based zeolites with the CHA, AEI, DDR, ITE or RTH structures are aromatic polymethylbenzenes and their corresponding carbenium ions. ${ }^{13-}$ 16] The transformation of gem-methylated polymethylbenzenium intermediates, framed in red in Scheme 1, can proceed through two main competitive pathways. The side-chain pathway includes exo-methylation, methyl shift, and side-chain elimination steps and yields predominantly ethene, while the paring route starts with a ring-contraction step that forms cyclopentenyl cations after splitting off propene or butene. According to this aromatics-based mechanism, the total amount of ethene, propene and butene finally obtained depends on the relative contribution of each of the two alternative pathways proposed to the total conversion of methanol.

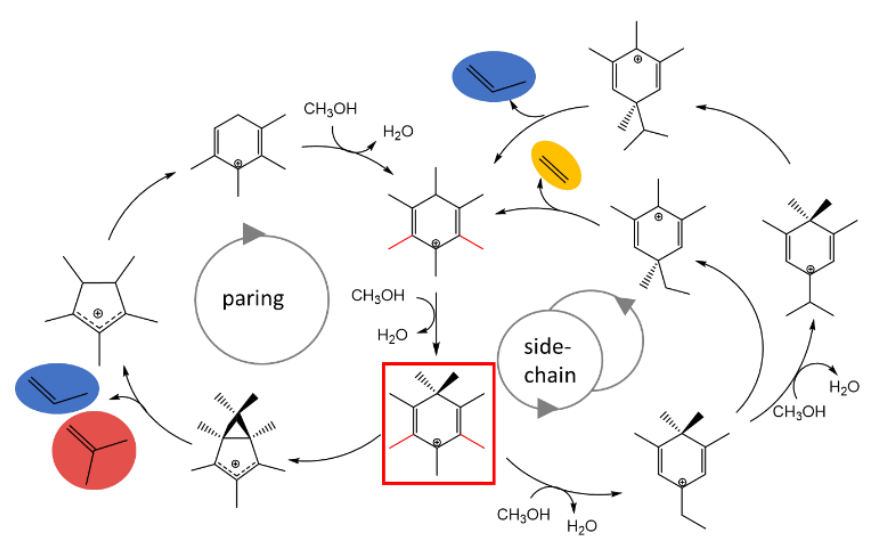

Scheme 1. Paring and side-chain pathways of the aromatics-based hydrocarbon pool mechanism proposed for the MTO reaction. The key gemmethylated polymethylbenzenium intermediate is framed in red. Based on reference ${ }^{[12]}$.

Previous kinetic and isotopic labeling studies proposed that the selectivity to ethene and propene depends on the degree of methylation of the aromatic intermediates, ${ }^{[17-19]}$ and a clear relationship between the dimensions and topology of the zeolite cavities and the short olefin product distribution in the MTO reactions was also demonstrated. ${ }^{[4,15,16,20-22]}$ Davis group introduced recently a structural parameter, the cage-defining ringsize, to classify fourteen different zeolite structures into four categories that differ in their product distribution. ${ }^{[22]}$ Going one step further, we combined DFT calculations with catalyst synthesis and testing to show that the MTO olefin product distribution is directly related to the degree of methylation of the entrapped poly-methyl-benzenium cations, which in turn is determined by the zeolite cavity architecture. ${ }^{[23,24]}$ Thus, the paring route is energetically accessible in cavities able to host and stabilize the fully methylated heptamethylbenzenium cation $\left(7 \mathrm{MB}^{+}\right)$, and consequently the production of propene is enhanced, while the preferential stabilization of the less substituted pentamethylbenzenium cation $\left(5 \mathrm{MB}^{+}\right)$leads to the side-chain pathway and a higher production of ethene. The ability of each cage to host $7 \mathrm{MB}^{+}$or $5 \mathrm{MB}^{+}$can be quantitatively described by the interaction energies between the cations and pure silica models of different cavities obtained from DFT calculations, and an 
interaction energy ratio or $E_{\text {int(7/5) }}$ parameter was established as descriptor of this relative stabilization. A linear relationship was found between the $\mathrm{C}_{3}=/ \mathrm{C}_{2}=$ ratios measured for different zeolites under different reaction conditions and the $E_{\text {int }(7 / 5)}$ parameter corresponding to each structure, thus confirming the confinement effect associated to cage topology as the factor governing the MTO product selectivity. ${ }^{[24]}$ However, the pure silica cluster models used in that study did not take into account the possible effect of acid site concentration or distribution, nor the influence of framework composition on the MTO reactivity. In this sense, it is interesting to compare the catalytic behavior of pairs of zeolites (aluminosilicates) and SAPOs (silicoaluminophosphates) with the same framework crystallographic structure but different framework composition, such as for instance $\mathrm{H}-\mathrm{SSZ}-13$ and $\mathrm{H}$ SAPO-34 with the CHA structure, or H-SSZ-39 and H-SAPO-18 with the AEI structure (Figure 1).

a)
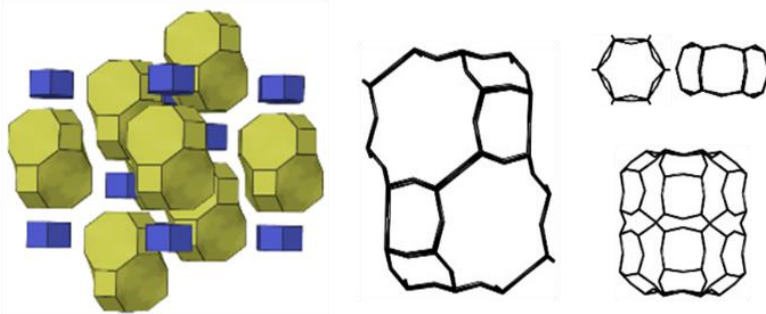

b)
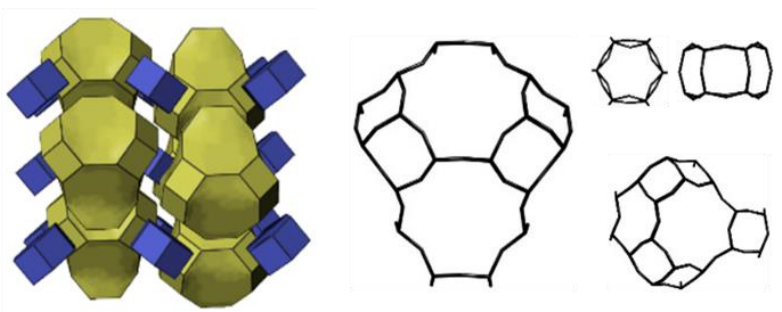

Figure 1. Structures of a) $\mathrm{CHA}$ and b) AEl frameworks.

Both crystallographic structures are composed by double sixmembered ring units $(d 6 r)$ that link to form cavities connected by eight-membered rings $(8 r)$ with a similar pore opening of $3.8 \AA$ in diameter, but the shape of the resulting cavities is clearly different. The CHA cages are cylindrical whereas AEI presents a basketlike topology with a wider part (see Figure 1). This particular shape of the AEI cavity allows a better stabilization of the $7 \mathrm{MB}^{+}$ intermediate that leads to a large production of propene when either H-SSZ-39 or H-SAPO-18 catalysts are tested in the MTO reaction. Thus, a product distribution consisting of $\sim 50 \%$ propene and similar amounts of ethene and butene, around $20 \%$ each, have been reported for the two AEI-based catalysts independently of their framework composition. ${ }^{21,22,24-28]}$ In contrast, CHA-type catalysts tend to produce more ethene and much less propene and butene, but there are differences in product distribution associated to framework composition. H-SSZ13 always produces more ethene than propene, $45 \%$ and $35 \%$ respectively, while the opposite relationship is always found for $\mathrm{H}$ SAPO-34. ${ }^{21,22,24,29-31]}$

One factor that could be invoked to explain this behavior is the lower acid strength of SAPOs as compared to zeolites, that leads to a lower optimal reaction temperature for the more acidic zeolites and might also have an impact on the reaction mechanism. ${ }^{[29,30]}$ The different framework flexibility of SAPOs and zeolites could also be claimed as the origin of these observations, since the diffusion of the larger olefins might be enhanced in the more flexible SAPO catalysts. ${ }^{[32-35]}$ However, the fact the MTO product selectivity varies with framework composition in $\mathrm{CHA}$ structures but remains similar in AEI-type catalysts indicates that the subject is not simple and requires a detailed study of each factor, i.e., acidity, framework flexibility and olefin diffusion, separately. In this work, we use periodic density functional theory (DFT) to analyze the impact of acid site location and framework flexibility on the stabilization of the key MTO reaction intermediates determining the mechanism, and ab initio molecular dynamics (AIMD) simulations to study the diffusion of ethene and propene through the $8 r$ windows of zeolites and SAPOs. Catalyst testing combined with the theoretical information allow to connect the higher flexibility of SAPO-34 with a better stabilization of $7 \mathrm{MB}^{+}$ and a higher propene production, and lead to a more generalized correlation between olefin product distribution and $E_{\text {int(7/5) }}$ parameter in small-pore cage-based zeolites and zeotypes.

\section{Results and Discussion}

\section{Catalyst synthesis, characterization and catalytic activity tests}

First, a systematic evaluation of the catalytic performance of zeolites and SAPOs with the $\mathrm{CHA}$ and $\mathrm{AEI}$ structures with different physico-chemical properties was performed to unambiguously establish the trends in product distribution. $\mathrm{H}$ SSZ-13 (CHA) and H-SSZ-39 (AEI) aluminosilicate zeolites, as well as H-SAPO-34 (CHA) and H-SAPO-18 (AEI) silicoaluminophosphate zeotypes were synthesized following the procedures described in detail in the Supporting Information. The as-synthesized materials show the characteristic PXRD patterns of $\mathrm{CHA}$ and $\mathrm{AEI}$ structures (Figure S1), and the textural properties of the calcined materials as determined by $\mathrm{N}_{2}$ adsorption experiments are analogous to those reported in the literature (Table S1). The catalyst samples were prepared with different chemical composition and crystal size (Table S1 and Figures S2S3). H-SSZ-13 zeolite was prepared with Si/Al molar ratios of 16 , either as nano-crystals of $\sim 60 \mathrm{~nm}$ (SSZ-13_2) or as micronsized particles of $\sim 1 \mu \mathrm{m}$ (SSZ-13_1), whereas the isostructural $\mathrm{H}$ SAPO-34 was also obtained as micron-sized crystals of $\sim 1 \mu \mathrm{m}$ with a Si/TO $/ \mathrm{TO}_{2}$ molar ratio of 0.09 (SAPO-34). H-SSZ-39 was synthesized with a Si/Al molar ratio close to 9 and different crystal sizes, from nanocrystallites of $\sim 60 \mathrm{~nm}$ (SSZ-39_2) to larger crystals of $\sim 700 \mathrm{~nm}$ (SSZ-39_1). Finally, two samples of H-SAPO18 were synthesized with $\mathrm{Si} / \mathrm{TO}_{2}$ molar ratios of 0.08 and with small ( 150 nm, SAPO-18_1) and large ( $800 \mathrm{~nm}$, SAPO-18_2) crystal sizes. The ${ }^{29} \mathrm{Si}$ and ${ }^{27} \mathrm{Al}$ MAS NMR spectra of the calcined samples reveal that most of the $\mathrm{Si}$ and $\mathrm{Al}$ species remain in tetrahedral coordination within the zeotype and zeolite frameworks, respectively (See Figure S4).

The catalytic performance of these materials in the MTO reaction was tested at $623 \mathrm{~K}$ and $673 \mathrm{~K}$, with a WHSV of $0.8 \mathrm{~h}^{-1}$ (see Table 1 and Figures 2, S5-S15). In agreement with previous work, when zeolites with the same structure and composition are compared at $623 \mathrm{~K}$ (SSZ-13_1 and SSZ-13_2, SSZ-39_1 and SSZ-39_2), larger catalysts lifetimes are observed for the samples with smaller particle size. In contrast, the selectivity to the different olefins formed, i.e., ethene, propene, and butene, is better 
correlated with the framework topology. The two H-SSZ-13 catalysts with different $\mathrm{Si} / \mathrm{Al}$ ratio and crystal size produce preferentially ethene, with $\sim 46 \%$ selectivity at $95 \%$ methanol conversion, and the $\mathrm{C}_{3}=/ \mathrm{C}_{2}=$ and $\mathrm{C}_{4}=/ \mathrm{C}_{2}=$ ratios are similar for both materials, $\sim 0.8$ and $\sim 0.3$ (see Table 1). In contrast, the two $\mathrm{H}$ SSZ-39 catalysts preferentially produce propene, with $46 \%$ selectivity at $95 \%$ methanol conversion, and nearly equivalent amounts of ethene and butene, $\sim 20 \%$ each, resulting in $\mathrm{C}_{3}=/ \mathrm{C}_{2}=$ and $\mathrm{C}_{4}=/ \mathrm{C}_{2}=$ ratios of $\sim 2.2$ and $\sim 1.0$, respectively (see Table 1 ). Moreover, these product distributions and ratios mostly remain constant during the MTO reaction under the studied conditions (see Figures 2, S5, S6, S8 and S9), even during catalyst deactivation when methanol conversion values are below $100 \%$.

Table 1. Product selectivity at the same methanol conversion level $(X=95 \%)$ for the different small pore zeolites and zeotypes and catalyst lifetime. Reaction conditions: $\mathrm{T}=623$ or $673 \mathrm{~K}, \mathrm{WHSV}=0.8 \mathrm{~h}^{-1}, \mathrm{w}_{\mathrm{cat}}=50 \mathrm{mg}$

\begin{tabular}{llllllll}
\hline & & $\begin{array}{c}\text { Time } \\
\text { (min) }\end{array}$ & $\begin{array}{l}\text { Selectivity } \\
(\% \mathbf{w})\end{array}$ & & Ratios & \\
\hline Sample & $\mathbf{T}(\mathbf{K})$ & $\mathbf{X}_{95}$ & $\mathbf{C}_{2}=$ & $\mathbf{C}_{3}=$ & $\mathbf{C}_{4}=$ & $\mathbf{C}_{3}=/ \mathbf{C}_{2}=$ & $\mathbf{C}_{\mathbf{4}}=/ \mathbf{C}_{2}=$ \\
\hline SSZ-13_1 & 623 & 260 & 45.1 & 37.0 & 12.4 & 0.82 & 0.27 \\
SSZ-13_2 & 623 & 1085 & 47.1 & 34.2 & 12.1 & 0.73 & 0.26 \\
SAPO-34 & 623 & 447 & 33.6 & 45.9 & 13.7 & 1.40 & 0.41 \\
SSZ-39_1 & 623 & 267 & 20.9 & 44.4 & 19.6 & 2.12 & 0.94 \\
SSZ-39_2 & 623 & 480 & 22.6 & 47.9 & 22.0 & 2.20 & 0.98 \\
SAPO-18_1 & 623 & 138 & 22.9 & 47.8 & 21.0 & 2.09 & 0.92 \\
SAPO-18_2 & 623 & 246 & 22.8 & 48.4 & 18.7 & 2.12 & 0.82 \\
\hline SSZ-13_1 & 673 & 670 & 56.4 & 30.4 & 9.2 & 0.54 & 0.16 \\
SAPO-34 & 673 & 298 & 37.9 & 41.8 & 13.4 & 1.10 & 0.35 \\
SSZ-39_1 & 673 & 446 & 33.6 & 44.5 & 14.2 & 1.32 & 0.42 \\
SAPO-18_2 & 673 & 471 & 34.5 & 46.4 & 13.2 & 1.34 & 0.38 \\
\hline
\end{tabular}

When catalysts with the same framework topology but different composition are compared, i.e., H-SSZ-13 with H-SAPO-34 and H-SSZ-39 with H-SAPO-18, two different situations appear. For CHA-type catalysts framework composition affects the product distribution, and the relative concentrations of ethene and propene obtained with $\mathrm{H}$-SSZ-13 zeolite are reversed in $\mathrm{H}$-SAPO34 (see Figures 2 and S7). H-SSZ-13 shows higher selectivity to ethene and less to propene at $623 \mathrm{~K}(\sim 46$ and $35 \%$, respectively, see Table 1) with $\mathrm{C}_{3}=/ \mathrm{C}_{2}=$ and $\mathrm{C}_{4}=/ \mathrm{C}_{2}=$ ratios of 0.8 and 0.26 , whereas, in the case of H-SAPO-34, propene is the most abundant olefin with $46 \%$ selectivity at $623 \mathrm{~K}$, resulting in an increase of the $\mathrm{C}_{3}=/ \mathrm{C}_{2}=$ and $\mathrm{C}_{4}=/ \mathrm{C}_{2}=$ ratios to 1.4 and 0.4 , respectively (see Table 1 ). In contrast, in catalysts with the $A E I$ structure, the composition of the framework does not alter the product distribution and very similar selectivity values and $\mathrm{C}_{3}=/ \mathrm{C}_{2}=$ and $\mathrm{C}_{4}=/ \mathrm{C}_{2}=$ ratios are obtained for $\mathrm{H}$-SSZ-39 and $\mathrm{H}-\mathrm{SAPO}-18$ samples (see Table 1 and Figures 2 and S8-S11). The $\mathrm{C}_{3}=/ \mathrm{C}_{2}=$ olefin ratios follow the order SSZ-13 < SAPO-34 < SSZ-39 SAPO-18, and this trend is maintained when the catalysts are tested at $673 \mathrm{~K}$ (Table 1 and Figures S12-S15).

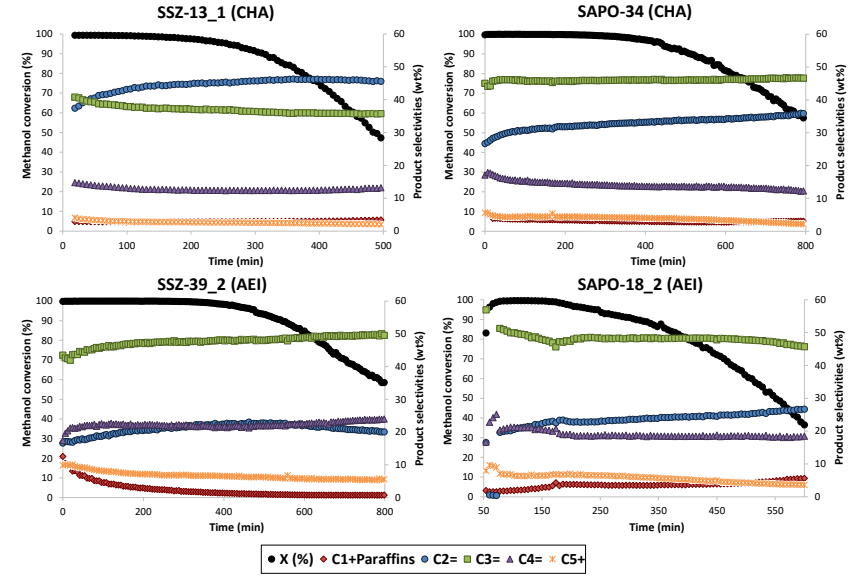

Figure 2. Methanol conversion and product selectivities (\%wt) with TOS using CHA-type (SSZ-13_1 and SAPO-34) and AEI-type (SSZ-39_2 and SAPO-18_2) catalysts (Reaction conditions: $\mathrm{T}=623 \mathrm{~K}, \mathrm{WHSV}=0.8 \mathrm{~h}^{-1}, \mathrm{w}_{\mathrm{cat}}=50 \mathrm{mg}$ ).

Periodic DFT study of the stability of reaction intermediates Framework flexibility. The three-dimensional pore systems of $\mathrm{CHA}$ and $\mathrm{AEI}$ crystallographic structures contain small $d 6 r$ units that link to form larger cavities accessible through $8 r$ windows (see Figure 1). The global dimensions or total volume of the internal cavities in zeolites SSZ-13 and SSZ-39 are similar (see Table S2 in the Supporting Information), but their topology is clearly different. According to IZA database, ${ }^{[36]}$ changing the framework composition from silicate to aluminophosphate results in an increase of the unit cell volume of $2.1 \%$ for $\mathrm{CHA}$ and $1.6 \%$ for AEI structures. To confirm the ability of our computational approach to reproduce these trends the unit cell parameters and atomic positions of the SSZ-13, AIPO-34, SSZ-39 and AIPO-18 catalyst models were fully relaxed without restrictions and, in agreement with experiment, the AIPO-34 and AIPO-18 unit cell volumes obtained from the periodic DFT calculations are, respectively, 3.4\% and 3.1\% larger than the corresponding silica counterparts (see Table S2).

The larger unit cell volume of AIPO materials as compared to zeolites could help stabilizing the bulkier $7 \mathrm{MB}^{+}$intermediate, thus favoring the paring route and enhancing the formation of propene and butene, a fact that was experimentally observed in the case of H-SAPO-34 (see Table 1). To clarify this point, the interaction energies of $5 \mathrm{MB}^{+}$and $7 \mathrm{MB}^{+}$cationic intermediates with neutral frameworks of SSZ-13, AIPO-34, SSZ-39 and AIPO-18 catalysts were obtained from periodic DFT calculations. In a first set of calculations, the atoms of the zeolite or AIPO lattices were kept fixed to simulate rigid materials, and only the cationic intermediates were fully optimized without restrictions. In a second step, all the framework atoms were also allowed to relax to simulate flexible materials. In all cases, and as expected from the different acid strength of AIPOs and zeolites (see Table S3 and discussion in the Supporting Information), the calculated interaction energies are larger in the silicate models than in the aluminophosphates. But this effect is quite similar for both cations and therefore their relative stabilization, measured by the $E_{\text {int }(7 / 5)}$ parameter, is not affected by the catalyst composition when we consider rigid materials (see Table 2). Under these geometry constraints, $5 \mathrm{MB}^{+}$is always better stabilized than $7 \mathrm{MB}^{+}$because of its smaller size, and the $E_{\text {int }(7 / 5)}$ parameters calculated with fixed framework indicate, on one side, that the two AEI catalysts would 
produce more propene than the two $\mathrm{CHA}$ materials and, on the other side, that changing catalyst composition in $\mathrm{CHA}$ would have no effect on product distribution, while SAPO-18 would produce more propene than SSZ-39. This result clearly contradicts the experimental observations described above, and suggests that rigid models are not adequate to describe these systems.

Table 2. Interaction energies between the key reaction intermediates $5 \mathrm{MB}^{+}$and $7 \mathrm{MB}^{+}$and neutral catalyst models and $E_{\text {int(7/5) }}$ parameters calculated with fixed and relaxed frameworks.

\begin{tabular}{|c|c|c|c|c|c|c|}
\hline \multirow[b]{2}{*}{ Catalyst } & \multicolumn{3}{|c|}{ Fixed framework atoms } & \multicolumn{3}{|c|}{ Relaxed framework atoms } \\
\hline & $\begin{array}{c}\mathrm{E}_{\text {int }}\left(5 \mathrm{MB}^{+}\right) \\
(\mathrm{kJ} / \mathrm{mol})\end{array}$ & $\begin{array}{c}\text { Eint }_{\text {int }}\left(7 \mathrm{MB}^{+}\right) \\
(\mathrm{kJ} / \mathrm{mol})\end{array}$ & $E_{\text {int }(7 / 5)}$ & $\begin{array}{c}\mathrm{E}_{\text {int }}\left(5 \mathrm{MB}^{+}\right) \\
(\mathrm{kJ} / \mathrm{mol})\end{array}$ & $\begin{array}{c}\mathrm{E}_{\text {int }}\left(7 \mathrm{MB}^{+}\right) \\
(\mathrm{kJ} / \mathrm{mol})\end{array}$ & $E_{\text {int }(7 / 5)}$ \\
\hline SSZ-13 & -598 & -548 & 0.91 & -607 & -569 & 0.93 \\
\hline AIPO-34 & -590 & -536 & 0.91 & -598 & -565 & 0.95 \\
\hline SSZ-39 & -632 & -590 & 0.93 & -649 & -640 & 0.99 \\
\hline AIPO-18 & -619 & -602 & 0.97 & -623 & -619 & 1.00 \\
\hline
\end{tabular}

a)

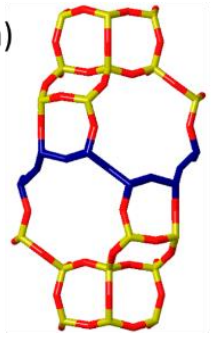

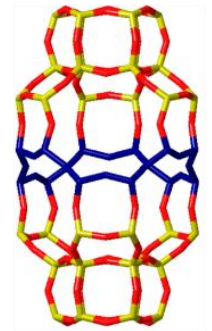

b)

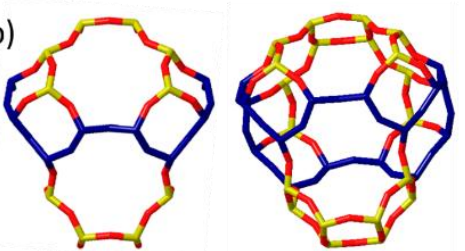

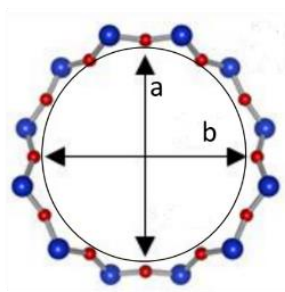

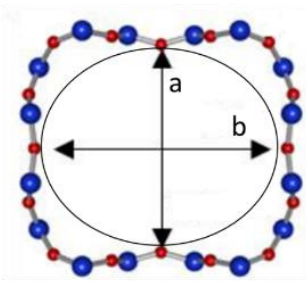

Figure 3. Cage defining ring in a) $\mathrm{CHA}$ and b) $\mathrm{AEI}$ frameworks.

When framework flexibility is included in the second set of calculations, interaction energies increase systematically due to a better accommodation of the cations inside the cavities, but the effect is more pronounced for the bulkier $7 \mathrm{MB}^{+}$intermediate. Indeed, while $E_{\text {int }}$ values for $5 \mathrm{MB}^{+}$increase from 4 to $17 \mathrm{~kJ} / \mathrm{mol}$, the extra stabilization achieved for $7 \mathrm{MB}^{+}$ranges from 17 to 50 $\mathrm{kJ} / \mathrm{mol}$, leading to significant differences in the $\mathrm{E}_{\text {int }(7 / 5)}$ parameters. The $E_{\text {int }(7 / 5)}$ values obtained with relaxed framework atoms for the two AEI catalysts are similar (see Table 2) and larger than those calculated for $\mathrm{CHA}$ materials, for which catalyst composition has an influence and the $E_{\text {int }(7 / 5)}$ parameter calculated for AIPO-34 is larger than for SSZ-13. To understand this effect, the geometry deformations that the entrapped hydrocarbon pool intermediates provoke in the four cavities considered have been analyzed in detail (see Figure 3 and Table 3). According to Davis ${ }^{[22]}$ the cagedefining ring encircles the center of the cages in cage-based zeolites, that is, it is the ring enclosing the cationic intermediates of the MTO reaction, and its size can be defined as the number of tetrahedral atoms of the ring, 12 for $\mathrm{CHA}$ and 16 for $\mathrm{AEI}$. The cage-defining ring can also be considered as an ellipse whose area can be more accurately estimated from the $a$ and $b$ distances obtained from the geometry optimizations (see Figure 3). Empty cavities in AIPO-34 are initially larger than in SSZ-13 (see Table 3 ), and the presence of entrapped $5 \mathrm{MB}^{+}$and $7 \mathrm{MB}^{+}$cations leads to a systematic enlarging of the ellipse area in the flexible aluminophosphate. In contrast, the dimensions of the cages in the more rigid SSZ-13 framework can only increase slightly in the presence of entrapped cations, resulting in a low stabilization of the bulkier $7 \mathrm{MB}^{+}$. Notice that the ellipse area in empty AIPO-34 is larger than in SSZ-13 hosting $7 \mathrm{MB}^{+}$, which would explain the different stabilization of this intermediate in the two $\mathrm{CHA}$ catalysts.

Table 3. Cavity geometry deformation in neutral catalysts due to the presence of entrapped $5 \mathrm{MB}+$ and $7 \mathrm{MB}+$ cations. The ellipses used to define each cavity are shown in Figure 3.

\begin{tabular}{cccc}
\hline Catalyst & $\begin{array}{c}\text { Area of empty } \\
\text { cavity }\left(\AA^{2}\right)\end{array}$ & $\begin{array}{c}\text { Area with } \\
\mathbf{5 M B}^{+}\left(\AA^{2}\right)\end{array}$ & $\begin{array}{c}\text { Area with } \\
\mathbf{7 M B}^{+}\left(\AA^{2}\right)\end{array}$ \\
\hline SSZ-13 & 40.6 & 41.9 & 41.8 \\
AIPO-34 & 41.9 & 42.1 & 43.2 \\
SSZ-39 & 47.9 & 45.6 & 45.9 \\
AIPO-18 & 48.2 & 42.5 & 43.9 \\
\hline
\end{tabular}

The situation is completely different in the catalysts with the AEI structure. The area of the ellipse in the empty SSZ-39 and AIPO18 cavities is much larger than in the empty cavities of SSZ-13 and AIPO-34, and the presence of entrapped $5 \mathrm{MB}^{+}$and $7 \mathrm{MB}^{+}$ cations leads to a contraction of the ring to try to increase the stabilizing interactions between the organic cations and the framework oxygens. Again, the geometry deformation is easier in the more flexible AIPO-18 than in the more rigid zeolite SSZ-39, and the final optimized area of the ellipse containing the cationic intermediates in the less restricted AIPO-34 and AIPO-18 materials are quite similar. The larger cage-defining ring size of AEI (16T atoms) as compared to CHA (12T atoms) could explain the easier deformation of the AEI cavity to stabilize entrapped organic cations, irrespectively of the framework composition. It can be concluded form these data that framework flexibility favors the stabilization of $7 \mathrm{MB}^{+}$in AIPO-34 as compared to SSZ13 , but the effect is almost negligible/less important in catalysts with the AEI structure. The calculated $E_{\text {int(7/5) }}$ parameters follow the order SSZ-13 < AIPO-34 < SSZ-39 $\leq$ AIPO-18, in good agreement with the $\mathrm{C}_{3}=/ \mathrm{C}_{2}=$ olefin ratio experimentally measured (see Table 1)

Acid site location. The neutral models employed in previous section are able to capture the confinement effect associated to framework architecture or cavity topology, but do not contain the Brönsted acid sites responsible for the catalytic activity of zeolites and SAPOs. Al atoms in zeolites and $\mathrm{Si}$ atoms in SAPOs can occupy different framework positions around the confined intermediates, and the different interactions arising might have an impact or not on product distribution. To clarify this point Brönsted acid sites were created in different positions of $\mathrm{CHA}$ and $\mathrm{AEI}$ structures by introducing $\mathrm{Al}$ and $\mathrm{Si}$ in silicates and aluminophosphates, respectively, thus generating several $\mathrm{H}$ SSZ-13, H-SAPO-34, H-SSZ-39 and H-SAPO-18 models (see Figure 4). The interaction of the cationic intermediates with the 
negatively charged heteroatom-containing catalyst models was evaluated and the results are summarized in Table 4. a)

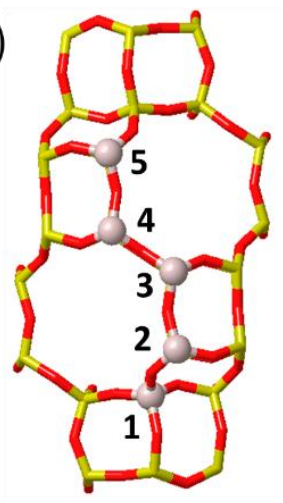

b)

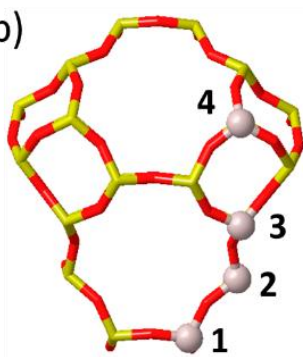

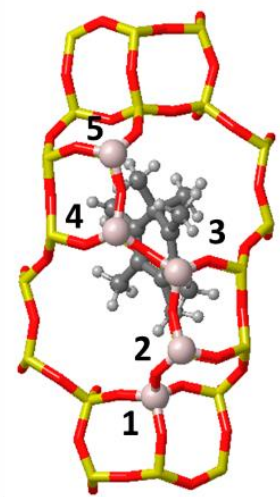

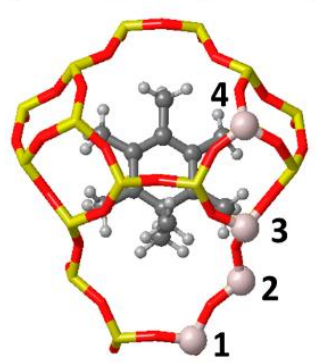

Figure 4. Acid site location in a) $\mathrm{CHA}$ and b) AEI frameworks.

Table 4. Interaction energies (in $\mathrm{kJ} / \mathrm{mol}$ ) between the key reaction intermediates and active-site containing catalyst models and $E_{\text {int(7/5) }}$ parameters.

\begin{tabular}{ccccc}
\hline & $\mathrm{T}$ & $\begin{array}{c}\mathrm{E}_{\text {int }}\left(5 \mathrm{MB}^{+}\right) \\
(\mathrm{kJ} / \mathrm{mol})\end{array}$ & $\begin{array}{c}\mathrm{E}_{\text {int }}\left(7 \mathrm{MB}^{+}\right) \\
(\mathrm{kJ} / \mathrm{mol})\end{array}$ & $\mathrm{E}_{\text {int }}(7 / 5)$ \\
\hline SSZ-13 & 1 & -561 & -515 & 0.92 \\
& 2 & -561 & -519 & 0.92 \\
& 3 & -573 & -527 & 0.92 \\
& 4 & -577 & -527 & 0.91 \\
& 5 & -569 & -519 & 0.92 \\
\hline AIPO-34 & 1 & -552 & -527 & 0.96 \\
& 3 & -552 & -536 & 0.97 \\
& 5 & -552 & -527 & 0.96 \\
\hline SSZ-39 & 1 & -619 & -611 & 0.99 \\
& 2 & -628 & -619 & 0.99 \\
& 3 & -615 & -607 & 0.99 \\
& 4 & -615 & -607 & 0.99 \\
\hline AIPO-18 & 2 & -594 & -594 & 1.00 \\
& 3 & -594 & -594 & 1.00
\end{tabular}

As a general rule, the heteroatom locations closer to the positive charge in the cationic intermediates result in a better stabilization (see Figure 4 and Table 4). But taking into account that the positive charge in $5 \mathrm{MB}^{+}$and $7 \mathrm{MB}^{+}$is highly delocalized and the large number of van der Waals interactions/contacts with framework oxygen atoms contributing to the stabilization by confinement, the differences in stability associated to $\mathrm{Al}$ or $\mathrm{Si}$ position are relatively small, less than $16 \mathrm{~kJ} / \mathrm{mol}$ in the zeolites and almost negligible in the SAPOs. Moreover, the order of stability is the same for $5 \mathrm{MB}^{+}$and $7 \mathrm{MB}^{+}$, so that the $\mathrm{E}_{\text {int(7/5) }}$ parameters are almost independent of heteroatom location. Interestingly, the $E_{\text {int }(7 / 5)}$ values obtained using more realistic active-site containing models (0.92 for $\mathrm{H}$-SSZ-13, 0.96 for $\mathrm{H}$ SAPO-34, 0.99 for H-SSZ-39 and 1.00 for H-SAPO-18) are nearly the same as those obtained considering neutral $\mathrm{SiO}_{2}$ and AIPO frameworks (see Table 2), confirming that cavity architecture is the key factor determining the stability of the entrapped carbocationic intermediates. Indeed, a linear relationship is found between $\mathrm{C}_{3}=/ \mathrm{C}_{2}=$ ratios and $\mathrm{E}_{\text {int }(7 / 5)}$ parameters for the zeolites and zeotypes considered, either measured in this work (Figure $5 \mathrm{a}$ ) or reported in bibliography using other reaction conditions (Figure $5 b) \cdot{ }^{[22]}$

a)

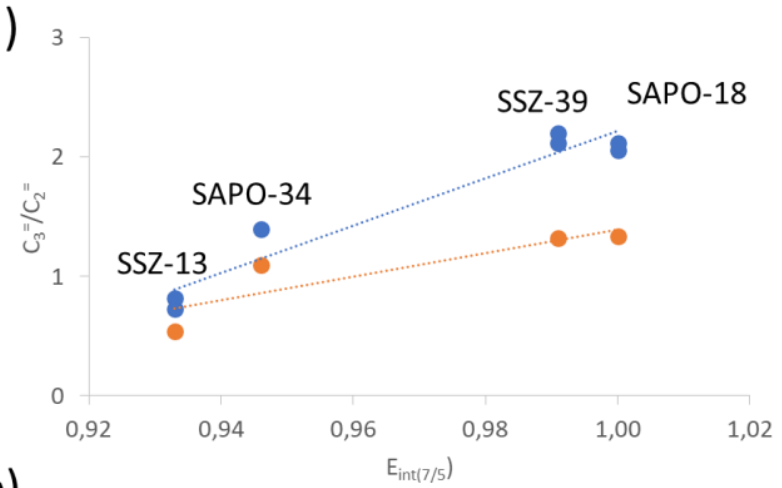

b)

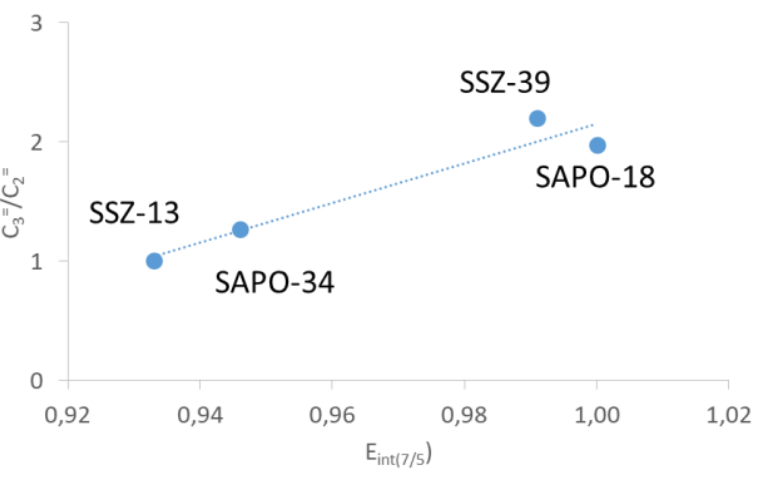

Figure 5. Relationship between measured $\mathrm{C}_{3}=/ \mathrm{C}_{2}=$ ratio and $\mathrm{E}_{\text {int }(7 / 5)}$ parameter in small-pore cage-based zeolites and zeotypes. Reaction conditions: a) WHSV $=0.8 \mathrm{~h}^{-1}, \mathrm{~T}=673 \mathrm{~K}$ (orange) and $\mathrm{T}=623 \mathrm{~K}$ (blue), data from this work, b) $W H S V=1.3 h^{-1}, T=673 \mathrm{~K}$, data from reference ${ }^{[22]}$.

\section{AIMD study of olefin diffusion through $8 r$ windows in CHA}

The larger cavity size and higher flexibility of SAPOs as compared to zeolites might also have an influence on the relative diffusion rate of the olefin products, mainly ethene and propene. Previous experimental studies have shown that ethene diffuses faster than propene in small-pore cage-based zeolites, and that the relative diffusion rate depends on multiple factors such as temperature, window size, catalyst composition or coke content. ${ }^{[2,37-39]}$ It has been reported that the diffusion of ethene in all silica SSZ-13 at $303 \mathrm{~K}$ is 80 times faster than that of propene, but the ethene/propene diffusivity ratio is reduced to 28 times at $353 \mathrm{~K},{ }^{[37]}$ and might further decrease at the MTO reaction temperature, 623 $\mathrm{K}$. In contrast, the diffusion coefficients of ethene and propene in SAPO-34 are quite similar even at low temperature, with a reported diffusivity ratio of 1.7 at $323 \mathrm{~K} \cdot{ }^{[38]}$ Therefore, if propene diffusion is preferentially enhanced in the more flexible SAPOs, a higher $\mathrm{C}_{3}=/ \mathrm{C}_{2}=$ ratio would be experimentally observed without the need to invoke mechanistic differences.

Molecular dynamics simulations have demonstrated that olefin diffusion in small-pore cage-based zeolites is a hindered process, where olefins remain most of time in one cavity and occasionally 
hop to a neighboring cavity crossing the 8 r window. ${ }^{[33-35]}$ Recently, Cnudde et al. ${ }^{[35]}$ used enhanced sampling molecular dynamics simulations to analyze the influence of Brönsted acid sites and entrapped hydrocarbon pool intermediates on the diffusion of ethene and propene in H-SAPO-34. It was confirmed that the activation barriers for ethene diffusion are lower than for propene, and it was found that the presence of Brönsted acid sites does not change this trend. However, a direct comparison of ethene and propene in SSZ-13 and SAPO-34 materials using the same methodology is still missing, so that the role of olefin diffusion on the MTO product distribution obtained with CHA-type catalysts is not established yet. To clarify this point, we have investigated the diffusion of ethene and propene through the $8 r$ windows of SSZ13 and AIPO-34 catalyst models by means of ab initio molecular dynamics simulations at the reaction temperature (623 K), using enhanced umbrella sampling techniques.

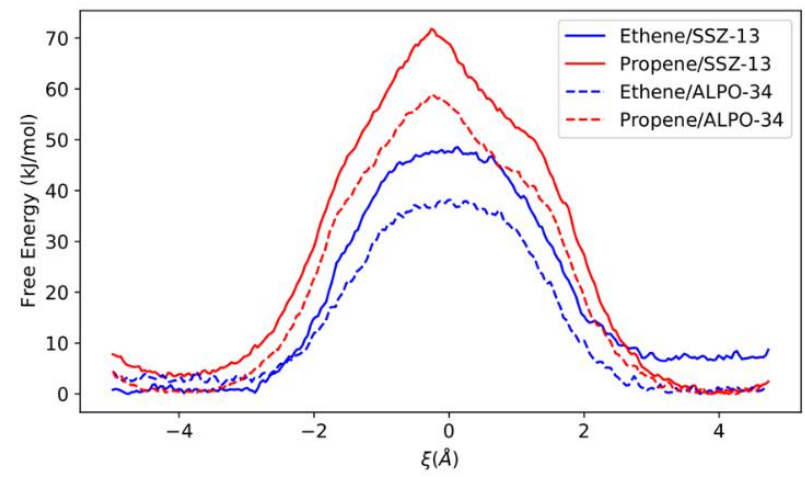

Figure 6. Free energy profiles for olefin diffusion through the $8 r$ windows of CHA-type catalyst from umbrella sampling AIMD simulations at $623 \mathrm{~K}$.

Table 5. Gibbs free energy barriers (in $\mathrm{kJ} / \mathrm{mol}$ ) and geometry changes for short olefin diffusion through the $8 r$ windows of $\mathrm{CHA}$ catalyst models from umbrella sampling AIMD simulations at $623 \mathrm{~K}$.

\begin{tabular}{lcccc}
\hline \multicolumn{1}{c}{ Catalyst } & ethene & propene & ethene & propene \\
\hline Activation barrier $(\mathrm{kJ} / \mathrm{mol})$ & 49 & 72 & 38 & 59 \\
$8 \mathrm{r}$ area in empty cell $\left(\AA^{2}\right)$ & \multicolumn{2}{c}{33.2} & \multicolumn{2}{c}{34.0} \\
8 r area at $\xi=-4\left(\AA^{2}\right)$ & 33.0 & 32.9 & 33.9 & 33.9 \\
8 r area at $\xi=0\left(\AA^{2}\right)$ & 34.8 & 35.5 & 35.6 & 36.3 \\
8 r area expansion $(\%)$ & 5.4 & 7.9 & 5.0 & 7.8 \\
\hline
\end{tabular}

The free energy profiles in Figure 6 are nearly symmetrical, with the minima being found at $\xi=-4 \AA$ and $\xi=4 \AA$, that is, in the center of the initial and final cavities, and with the highest energy corresponding to the olefin placed in the plane of the $8 r$, at $\xi=0$ $\AA$ (see Figure 7 and S16). The calculated free energy activation barriers in AIPO-34, $38 \mathrm{~kJ} / \mathrm{mol}$ for ethene and $59 \mathrm{~kJ} / \mathrm{mol}$ for propene (see Table 5) are in excellent agreement with previously reported data using a similar methodology. ${ }^{[35]}$ The AIMD barriers for ethene and propene diffusion in SSZ-13 are $49 \mathrm{~kJ} / \mathrm{mol}$ and 72 $\mathrm{kJ} / \mathrm{mol}$, respectively, that is, both of them $\sim 12 \mathrm{~kJ} / \mathrm{mol}$ larger than in AIPO-34.
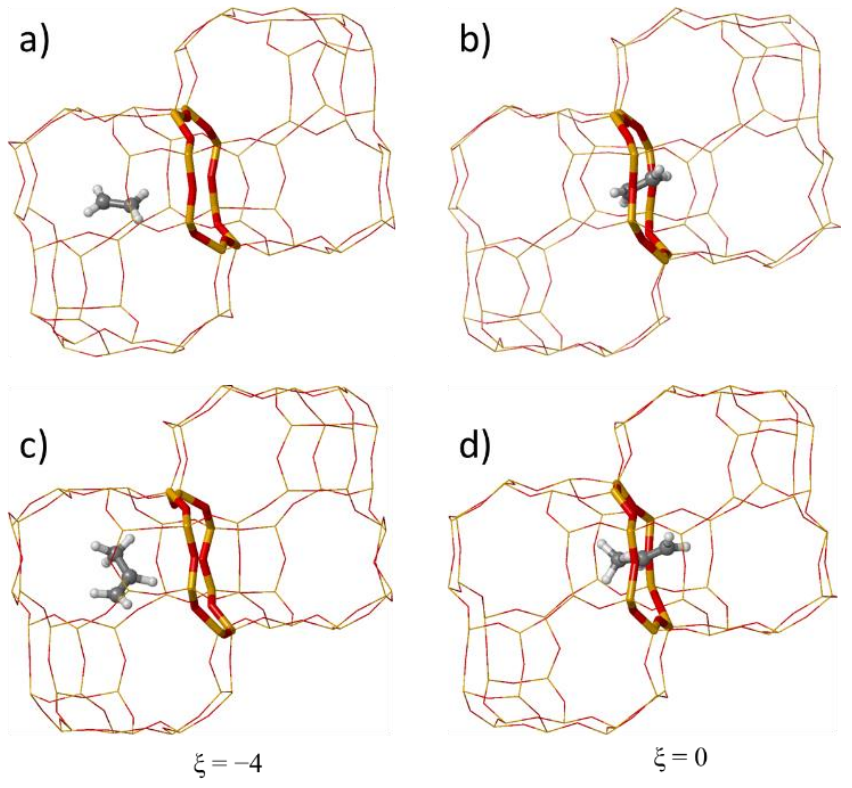

Figure 7. Snapshots of the local minima $(a, c)$ and transition states $(b, d)$ on the free energy surface corresponding to ethene $(a, b)$ and propene $(c, d)$ diffusion through the $8 r$ windows of SSZ-13 rom umbrella sampling AIMD simulations at $623 \mathrm{~K}$.
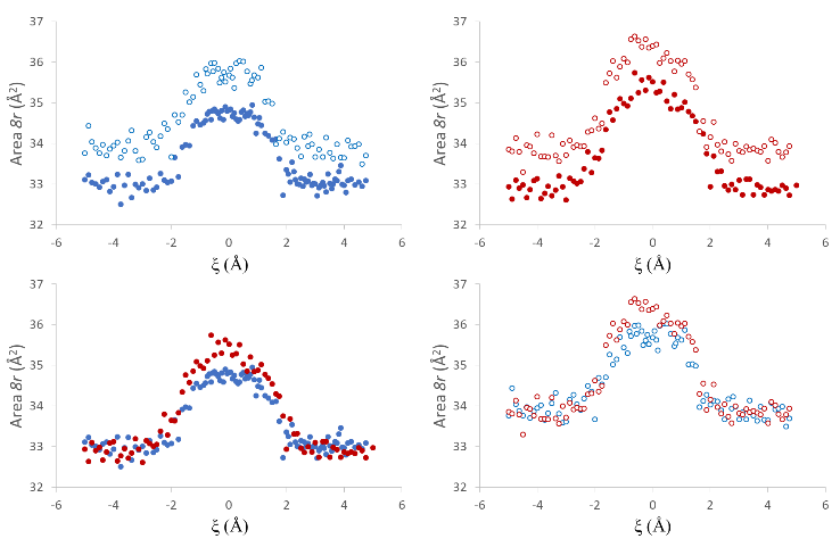

Figure 8. Expansion of the $8 r$ window area in CHA-type catalysts due to diffusion of ethene (blue) and propene (red) through SSZ-13 (solid circles) and AIPO-34 (empty circles) obtained from umbrella sampling AIMD simulations at $623 \mathrm{~K}$.

This trend could be tentatively associated to the higher flexibility of the AIPO framework that allows an expansion of the $8 r$ window when olefins are crossing. However, analysis of the average geometries obtained from the AIMD simulations (see Figure 8) shows that the $8 r$ windows are already larger in AIPO-34 than in SSZ-13 in the structures with ethene or propene adsorbed in the cavities, and in all cases this area increases about $6-7 \%$ to facilitate the crossing of the olefins from one cavity to another one (see Table 5). The more flexible AIPO-34 framework allows an expansion of $2.0 \AA^{2}$ and $2.2 \AA^{2}$ for ethene and propene diffusion, respectively, while the more rigid SSZ-13 is able to expand the ring area $1.9 \AA^{2}$ for ethene and $2.3 \AA^{2}$ for propene. These data suggest that the lower diffusion barriers obtained for AIPO-34 are not due to a higher flexibility, but to the initially/intrinsically larger $8 r$ windows in this material. 
The AIMD results presented here confirm that propene diffusion is hindered compared to ethene, and that diffusion of olefins is faster/easier in AIPO-34 than in SSZ-13. But the difference in the diffusion barriers for propene and ethene $\left(\mathrm{G}_{\mathrm{act}} \mathrm{C}_{3}{ }^{=}-\mathrm{G}_{\mathrm{act}} \mathrm{C}_{2}{ }^{=}\right)$has a similar value of $\sim 12 \mathrm{~kJ} / \mathrm{mol}$ in both materials, indicating that the higher flexibility of the AIPO framework does not lead to a preferential enhancement of propene diffusion rate. Therefore, the higher $\mathrm{C}_{3}=/ \mathrm{C}_{2}=$ ratio experimentally obtained when H-SAPO34 is used as catalyst for the MTO reaction cannot be attributed to a faster diffusion of propene in this catalyst.

It should be mentioned at this point that additional diffusion limitations due to formation of bulky carbonaceous species such as polyaromatics and coke cannot be excluded from these calculations. However, the AIMD simulations by Cnudde et al. ${ }^{[35]}$ showed that olefins can only diffuse through empty cavities, and we recently presented an optimized $\mathrm{H}$-SSZ-13 catalyst with a controlled $\mathrm{Al}$ distribution that avoids the formation of $\mathrm{HP}$ intermediates in all the cavities, thus facilitating the product diffusion through the empty cages. ${ }^{[31]}$ These considerations, together with the clear differences in product distribution obtained from the beginning of the reaction for H-SSZ-13 and H-SAPO-34 (see Figure 2 and S5-S15) and the fact that they remain constant during the whole catalyst lifetime, support our proposal that selectivity is not mainly controlled by diffusion. ${ }^{[40]}$

\section{Conclusion}

\section{Conclusion}

The main factors that have been proposed to control the olefin product distribution of the MTO reaction catalyzed by small-pore cage-based zeolites and zeotypes have been analyzed though a combination of static DFT calculations, AIMD simulations and catalytic activity tests. Catalyst samples differing in framework topology (CHA and AEI) and composition (zeolite and SAPO) exhibit different selectivity to ethene, propene and butene. The cavity topology and its ability to preferentially stabilize the fully methylated $7 \mathrm{MB}^{+}$cations involved in the paring mechanism is the key factor controlling product distribution, as confirmed by the linear relationship between the experimentally determined $\mathrm{C}_{3}=/ \mathrm{C}_{2}=$ ratio and the $E_{\text {int(7/5) }}$, parameter. The strength, amount and location of the Brönsted acid sites in the catalyst structure has a minor influence, but the larger volume and framework flexibility of silicoaluminphosphates is key to explain the selectivity differences between SSZ-13 and SAPO-34. The accommodation of the bulky $7 \mathrm{MB}^{+}$cations in the cavities of $\mathrm{CHA}$-type catalysts requires an expansion of the $12 \mathrm{~T}$ rings enclosing them. This deformation is more energetically demanding in the more rigid zeolite, and consequently the final stabilization of $7 \mathrm{MB}^{+}$and the related $E_{\text {int(7/5) }}$ parameter are larger in the more flexible SAPO-34 than in SSZ-13 zeolite. In contrast, the relative diffusion rate of ethene and propene through $8 r$ windows is not modified by framework flexibility. Both olefins diffuse faster through the larger rings of SAPO-34, indicating that selectivity is not controlled by diffusion.

\section{Experimental Section}

Experimental information on synthesis, characterization and testing of catalysts, and computational details are given in the Supporting Information.

\section{Acknowledgements}

This work has been supported by the European Union through ERC-AdG-2014-671093 (SynCatMatch), Spanish Government through "Severo Ochoa" (SEV-2016-0683, MINECO), MAT201782288-C2-1-P (AEI/FEDER, UE) and RTI2018-101033-B-I00 (MCIU/AEI/FEDER, UE), and by Generalitat Valenciana through AICO/2019/060. The Electron Microscopy Service of the UPV is acknowledged for their help in sample characterization. Red Española de Supercomputación (RES) and Servei d'Informàtica de la Universitat de València (SIUV) are acknowledged for computational resources and technical support. P. F. and R. M. thank ITQ for their contracts. C.L. acknowledges China Scholarship Council (CSC) for a Ph.D fellowship..

Keywords: Ab initio calculations $\cdot$ diffusion $\cdot$ MTO $\cdot$ reaction mechanism $\bullet$ structure-selectivity relationship

\section{References}

[1] G. A. Olah, Angew. Chemie Int. Ed. 2005, 44, 2636-2639.

[2] P. Tian, Y. Wei, M. Ye, Z. Liu, ACS Catal. 2015, 5, 1922-1938.

[3] J. F. Haw, W. Song, D. M. Marcus, J. B. Nicholas, Acc. Chem. Res 2003, 36, 317-326.

[4] U. Olsbye, S. Svelle, M. Bjørgen, P. Beato, T. V. W. Janssens, F. Joensen, S. Bordiga, K. P. Lillerud, Angew. Chemie Int. Ed. 2012 51, 5810-5831.

[5] V. Van Speybroeck, K. De Wispelaere, J. Van der Mynsbrugge, M. Vandichel, K. Hemelsoet, M. Waroquier, Chem. Soc. Rev. 2014, 43 , 7326-7357.

[6] I. Yarulina, A. D. Chowdhury, F. Meirer, B. M. Weckhuysen, J. Gascon, Nat. Catal. 2018, 1, 398-411.

[7] M. Moliner, C. Martínez, A. Corma, Chem. Mater. 2014, 26, 246 258.

[8] D. M. McCann, D. Lesthaeghe, P. W. Kletnieks, D. R. Guenther, M. J. Hayman, V. Van Speybroeck, M. Waroquier, J. F. Haw, Angew. Chemie Int. Ed. 2008, 47, 5179-5182.

[9] C.-M. Wang, Y.-D. Wang, Z.-K. Xie, Z.-P. Liu, J. Phys. Chem. C 2009, 113, 4584-4591.

[10] S. llias, A. Bhan, ACS Catal. 2013, 3, 18-31.

[11] K. De Wispelaere, K. Hemelsoet, M. Waroquier, V. Van Speybroeck, J. Catal. 2013, 305, 76-80.

[12] K. Hemelsoet, J. Van der Mynsbrugge, K. De Wispelaere, M. Waroquier, V. Van Speybroeck, ChemPhysChem 2013, 14, 15261545.

[13] J. Li, Y. Wei, J. Chen, P. Tian, X. Su, S. Xu, Y. Qi, Q. Wang, Y. Zhou, Y. He, Z. Liu, J. Am. Chem. Soc. 2012, 134, 836-839.

[14] S. Xu, A. Zheng, Y. Wei, J. Chen, J. Li, Y. Chu, M. Zhang, Q. Wang Y. Zhou, J. Wang, F. Deng, Z. Liu, Angew. Chemie Int. Ed. 2013, 52, 11564-11568.

[15] J. Li, Y. Wei, J. Chen, S. Xu, P. Tian, X. Yang, B. Li, J. Wang, Z Liu, ACS Catal. 2015, 5, 661-665.

[16] W. Zhang, J. Chen, S. Xu, Y. Chu, Y. Wei, Y. Zhi, J. Huang, A. Zheng, X. Wu, X. Meng, F. Xiao, F. Deng, Z. Liu, ACS Catal. 2018, 8, 10950-10963.

[17] W. Song, H. Fu, J. F. Haw, J. Am. Chem. Soc. 2001, 123, 47494754.

[18] S. Svelle, U. Olsbye, F. Joensen, M. Bjørgen, J. Phys. Chem. C 2007, 111, 17981-17984

[19] A. Hwang, B. A. Johnson, A. Bhan, J. Catal. 2019, 369, 86-94

[20] Y. Bhawe, M. Moliner-Marin, J. D. Lunn, Y. Liu, A. Malek, M. Davis, ACS Catal. 2012, 2, 2490-2495.

[21] J. H. Kang, R. Walter, D. Xie, T. Davis, C.-Y. Chen, M. E. Davis, S. I. Zones, ChemPhysChem 2018, 19, 412-419.

[22] J. H. Kang, F. H. Alshafei, S. I. Zones, M. E. Davis, ACS Catal. 2019, 9, 6012-6019.

[23] C. Li, C. Paris, J. Martínez-Triguero, M. Boronat, M. Moliner, A. Corma, Nat. Catal. 2018, 1, 547-554. 
[24] P. Ferri, C. Li, C. Paris, A. Vidal-Moya, M. Moliner, M. Boronat, A. Corma, ACS Catal. 2019, 9, 11542-11551.

[25] J. Chen, J. Li, C. Yuan, S. Xu, Y. Wei, Q. Wang, Y. Zhou, J. Wang M. Zhang, Y. He, S. Xu, Z. Liu, Catal. Sci. Technol. 2014, 4, 3268. M. Dusselier, M. A. Deimund, J. E. Schmidt, M. E. Davis, ACS

[27] Catal. 2015, 5, 6078-6085. Chem. Commun. 2016, 52, 6072-6075.

[28] R. Martínez-Franco, Z. Li, J. Martínez-Triguero, M. Moliner, A. Corma, Catal. Sci. Technol. 2016, 6, 2796-2806.

[29] F. Bleken, M. Bjørgen, L. Palumbo, S. Bordiga, S. Svelle, K.-P. Lillerud, U. Olsbye, Top. Catal. 2009, 52, 218-228.

[30] C.-M. Wang, Y.-D. Wang, Y.-J. Du, G. Yang, Z.-K. Xie, Catal. Sci. Technol. 2015, 5, 4354-4364.

[31] E. M. Gallego, C. Li, C. Paris, N. Martín, J. Martínez-Triguero, M. Boronat, M. Moliner, A. Corma, Chem. - A Eur. J. 2018, 24, 1463114635.

[32] D. Chen, K. Moljord, A. Holmen, Microporous Mesoporous Mater. 2012, 164, 239-250.

[33] C. Wang, B. Li, Y. Wang, Z. Xie, J. Energy Chem. 2013, 22, 914918.

[34] A. Ghysels, S. L. C. Moors, K. Hemelsoet, K. De Wispelaere, M. Waroquier, G. Sastre, V. Van Speybroeck, J. Phys. Chem. C 2015, 119, 23721-23734.

[35] P. Cnudde, R. Demuynck, S. Vandenbrande, M. Waroquier, G Sastre, V. Van Speybroeck, J. Am. Chem. Soc. 2020, 142, 60076017.

[36] "Structure Commission of the International Zeolite Association (IZA$\mathrm{SC})$, Database of Zeolite structures," can be found under http://www.iza-structure.org/databases/, n.d.

[37] D. H. Olson, M. A. Camblor, L. A. Villaescusa, G. H. Kuehl, Microporous Mesoporous Mater. 2004, 67, 27-33.

[38] D. M. Ruthven, S. C. Reyes, Microporous Mesoporous Mater. 2007 104, 59-66.

[39] N. Hedin, G. J. DeMartin, W. J. Roth, K. G. Strohmaier, S. C. Reyes, Microporous Mesoporous Mater. 2008, 109, 327-334

[40] Z. Li, J. Martínez-Triguero, P. Concepción, J. Yu, A. Corma, Phys. Chem. Chem. Phys. 2013, 15, 14670. 


\section{Entry for the Table of Contents}

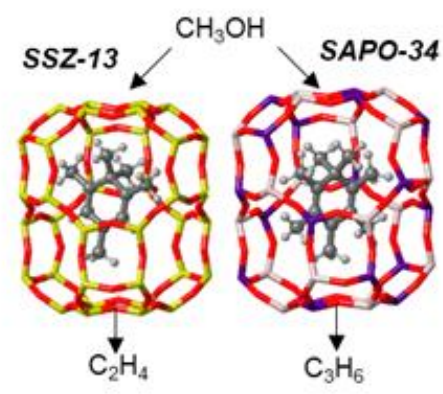

The higher flexibility of the SAPO-34 framework as compared to SSZ-13 does not modify the relative diffusion rate of ethene and propene, but facilitates the accommodation of the bulkier cationic intermediates involved in the paring route of the MTO reaction, thus increasing the production of propene and butene. 